\title{
Evde Bakım İçin Trakeostomili Olarak Taburcu Edilen Hastaların Sonuçlarının Değerlendirilmesi
}

\author{
To Evaluate the Clinical Outcome in Patients Discharged for Home Care \\ With Tracheostomy
}

\author{
Rafi Doğan, Betül Başaran, Hüseyin Ulaş Pınar, Mehmet Arslan \\ Başkent Üniversitesi Tıp Fakültesi, Anesteziyoloji ve Reanimasyon Anabilim Dalı, Konya, Türkiye
}

\section{ÖZET}

Amaç: Evde bakım için spontan solunum veya mekanik ventilatör (MV) desteği ile taburcu edilen trakeostomize hastaların evde yaşadıkları sorunların ve çözüm yollarının tespit edilmesi amaçlandı. Gereç ve Yöntem: 2004-2010 yılları arasında, genel yoğun bakım (YB) ünitemizden taburcu edilen 30 hastanın verilerini retrospektif olarak inceledik. Hastalar, yatış tanılarına göre serebrovasküler hastalık (SVH), kronik obstrüktif akciğer hastalı̆ı (KOAH) akut alevlenmesi ve diğerleri olmak üzere üç gruba ayrıldı. Hastaların Glasgow koma skorları (GKS), mekanik ventilatör desteği, evde yaşam süreleri, evde yaşanılan sorunlar ve ölüm nedenleri kaydedildi.

Bulgular: Hastaların \%80'i MV desteği ile taburcu edildi. \%23,3'ü hala yaşamaktadır. Yedi yıllık total mortalite oranları SVH, KOAH akut alevlenmesi ve diğerleri gruplarında sırasıyla \%92,8, \%66,6 ve \%57,1 idi. Taburculuktaki GKS düșük ve yaşı hastalarla evde yaşam süreleri düşük bulundu $(p<0,05)$. Evde en sık ölüm nedeni hava yolu sorunlarıydı.

Sonuç: Evde mortalitenin en önemli nedenleri hava yolu ve mekanik ventilatör sorunlarıydı. Bu sorunları azaltmak için daha sık hekim ziyareti gerektiği düşünülmektedir. GKS düşük trakeostomili hastaların evde bakım için taburcu edilmesindeki avantaj-dezavantaj oranını klinisyenlerin bir kez daha düşünmeleri gerektiğine inanıyoruz. (Türk Yoğun Bakım Derneği Dergisi 2011; 9: 99-102)

Anahtar Kelimeler: Trakeostomi, evde bakım, mekanik ventilasyon

\section{SUMMARY}

Objective: To present the patient's problems at home and the way of the solution in patients discharged for home care with tracheostomy. Method: 30 patients discharged from intensive care unit (ICU) between 2004-2010 years, were examined retrospectively. Patients were divided three groups as cerebrovascular accident (CVA), chronic obstructive pulmonary disease (COPD) acute exacerbation and the others, according to the diagnosis on admission. A Glasgow coma scores (GCS), mechanical ventilation (MV) support, survive at home, clinical problems at home, and cause of the death were recorded. Results: $80 \%$ of patients were discharged with MV. $23 \%$ of the patients are still alive. A total mortality rates were $92.8 \%$ in CVA, $66.6 \%$ in COPD acute exacerbation groups and $57.1 \%$ in the others. The survival time at home was significant correlate with GCS and patient's age $(p<0.05)$. The most frequent cause of the mortality at home was the airway problems.

Conclusion: The most important reason of the home mortality was airway and MV problems. To reduce these problems, the clinician must visit the patients more frequently. We belive that the clinicians must consider again, about the advantage-disadvantage on discharging of these patients for home care. (Journal of the Turkish Society Intensive Care 2011; 9: 99-102)

Key Words: Tracheostomy, home care, mechanical ventilation 


\section{Giriş}

Serebrovasküler hastalık (SVH) sekeli, ileri dönem kronik obstrüktif akciğer hastalığı (KOAH) akut alevlenmesi ve nöromüsküler hastalıklar genellikle kronik solunum yetmezliği ve/veya yutma güçlüğüne neden olup, hastaların büyük bir kısmı yoğun bakımda (YB) uzun dönem solunum desteğine ihtiyaç duymaktadır. Bu hastalara avantajlarından dolayı genellikle perkütan yolla olmak üzere trakeostomi açılmaktadır (1,2). Ancak bu hastaların uzun süre YB'da kalması Özellikle enfeksiyon, ekonomik ve sosyal entegrasyon sorunlarının ortaya çıkmasına neden olmaktadır. Ülkemizde bu tür hastaların bakımını yapacak merkezler yaygın olmadığı için evde bakım ile ilgili düzenlemeler gündeme gelmiştir. Bu hastalar için evde non-invaziv solunum desteği için yeni ventilatörler geliştirilmesine rağmen, uyum sorunu yaşayan veya yutma refleksi yeterli olmayan ve sekresyon kontrolünü sağlayamayan hastalarda solunum desteğinin trakeostomi ile sağlanması öncelik kazanmıştır. Bazı hastalar trakeostomiden sadece oksijen desteğiyle yeterli ventilasyon ve oksijenizasyonu sağlarken, bazıları mekanik ventilatör (MV) desteğine intiyaç duymaktadır. Çalışmalarda, uzun dönem trakeostomili hastaların rehabilitasyonunda evde bakımın, düşük maliyet, kaliteli sosyal destek ve yaşam kalitesinde artış açısından önemi vurgulanmıştır (3-5). Ancak bu hastalarda muhtemelen gelişen trakeostomi ya da MV sorunlarıyla ilgili elimizde yeterli bilgi bulunmamaktadır.

Çalışmanın amacı, trakeostomi ile evde bakım için taburcu edilen hastaların kısa ve uzun dönem sonuçlarının değerlendirilerek, evde yaşanılan sorunların ve çözüm yollarının tespit edilmesidir.

\section{Gereç ve Yöntem}

Çalışmamızda, 2004-2010 yılları arasında genel YB kliniğimizden trakeostomi ile evde bakım için taburcu edilen yaşları 31-93 arasında olan 15 erkek 15 bayan 30 hastanın tıbbi sonuçlarını retrospektif olarak değerlendirdik.

Trakeostomiler, Griggs (6) yöntemiyle perkütan trakeostomi seti (Portex Percutaneous Tracheostmy Kit, Smith Medical Australasia Pty. Ltd. Brisbane, Australia) kullanılarak açıldı. Hastalar, uzun dönem (7 günden fazla) MV desteğine ihtiyaç duyan, yutma güçlüğü ya da santral sinir sistemi yetmezliğinden hava yolunu koruyamayan kişilerdi. Trakeostomilerin kapatımama endikasyonları; hastaların MV desteğinin kesilememesi, hava yolunu koruyamamaları olarak belirlendi. Hastaların YB'a giriş ve çıkışlarındaki Glasgow koma skorlaması (GKS 1 ve GKS 2) değerlendirilerek kayıtları yapıldı. Hastalar yatış tanılarına göre, Grup 1: SVH $(n=14)$, Grup 2: KOAH akut alevlenmesi $(n=9)$, Grup 3: Diğerleri (postoperatif hastalar, sepsis, kronik böbrek yetmezliği, intoksikasyon, travma ( $n=7)$ olmak üzere 3 gruba ayrıldı.
Evde bakım nedeniyle trakeostomili olarak taburcu edilen hasların MV desteğinin olup olmayışı, evde hasta bakıcının hastayla ilgili yaşadığı sorunlar; havayolu sorunları (trakeal aspirasyonun yapılamaması, aşırı sekresyonlar ve tıkaç oluşumu, mide içeriği aspirasyonu trakeostomi kanül dislokasyonu) MV sorunları (ventilatörün basmaması, sık alarm vermesi, hava kaçağı olması, hastanın solunum sıkıntısının artması) ve diğer sorunlar (enfeksiyon, bası yarası), hastaların evde yaşadığı süre, mortalite oranları ve ölüm sebebi hasta yakınlarıyla telefon ile ya da yüz yüze görüşülerek kaydedildi. Ev tipi MV'ün ayarları en son YB'da aldığı MV desteğinin ayarlarına göre belirlendi.

Oral alamayan ya da yutkunma refleksi bozuk olan trakesostomili hastalara taburculuk öncesi gastroenteroloji uzmanı tarafından perkütan endoskopik yolla kalıcı gastrostomi (PEG) sondası yerleştirildi. Hastaların beslenme şekilleri kaydedildi.

Hastaların yakınlarından gönüllü olanlara taburculuk öncesi 1 hafta süreyle YB doktoru ve hemşiresi tarafından hava yolu kontrolü, trakeal aspirasyon ve MV ile ilgili teorik ve uygulamalı eğitim verildi. Eğitim sonunda yeterli görülen kişiler 1 hafta hastayı serviste hemşire kontrolünde takip etti. Serviste de hasta yakınının başarılı görülmesi üzerine hastanın taburculuğuna karar verildi. Hastaların taburculuktan 15 gün sonra YB hekimi tarafından ziyaret edileceği söylendi. Hasta bakıcının herhangi bir sorunla karşılaştığında YB hekimine ulaşıp sorunun çözümüyle ilgili bilgi alması belirtildi. Hasta bakıcıların YB hekimini aramaları ve içeriği kaydedildi.

Istatistiksel analiz, SPSS 17,0 programı yardımıyla yapıldı. Veriler sayı veya ortalama \pm standart sapma olarak sunuldu. Parametrik veriler bağımsız örneklem t-testi ile karşılaştırıldı. Verilerin birbiriyle ilişkilerinde Pearson korelasyon testi kullanıldı. $P \leq 0,05$ değeri istatistiksel olarak anlamlı kabul edildi

\section{Bulgular}

2004-2010 yılları arasında genel YB kliniğimizde trakeostomi açılan hastaların \%30,9'nu evde bakım için trakeostomili olarak taburcu ettik.

Tablo 1'de hasta demografik özellikleri verilmiştir. Grup 3'ün yaş ortalaması Grup 1 ve 2'ye göre anlamlı derecede küçüktü $(p<0,05)$. Evde yaşam süreleri açısından, istatistiksel olarak fark olmamasına karşın, en kısa süre Grup 1 hastalarına aittir. Ayrıca, evde ölen hasta sayısı ve MV desteğinin olup olmayışı açısından gruplar arasında anlamlı fark yoktu.

24 hasta (\%80) MV desteği ile gönderildi. 6 (\%20) tanesi 1 hafta içinde öldü ve hepsi de MV desteği alıyordu. Bu hastalarda ölüm nedenlerine bakıldığında 4'ünde hava yolu ile ilgili sorunlar, 1 'inde MV ile ilgili sorun varken 1'inde ise nedeni belli değildi. $7(\% 23,3)$ hasta hala yaşamaktadır ve bunların 5 tanesi (\%71) halen MV desteği almaktadır. Diğerleri farklı dönemlerde ölmüşlerdir. Yedi yıllık total 
Tablo 1. Gruplara göre hasta demografik verileri

$\begin{array}{ccc}\text { Grup 1 } & \text { Grup 2 } & \text { Grup 3 } \\ (n=14) & (n=9) & (n=7)\end{array}$

Yaş ortalaması (yıl) $74,50 \pm 9,88^{*} \quad 65,11( \pm 11,41)^{*} \quad 49,42 \pm 10,99 *$ Cinsiyet E/K $\quad 7 / 7 \quad 5 / 4 \quad 3 / 4$ EVS (hafta) $\quad 44,64 \pm 83,97 \quad 75,11 \pm 72,43 \quad 61,71 \pm 58,67$ EÖHS (n) \%92,8(13) \%66,6 (6) \%57,1 (4)

MV $\quad \% 85 \quad \% 55 \quad \% 100$

MV: Mekanik ventilasyon desteği, EVS: Evde yaşama süresi, EÖHS: Evde ölen hasta sayısı *:p<0.05

Tablo 2. Grupların Glasgow koma skorları karşılaştırmaları

\begin{tabular}{lcc} 
& GKS 1 & GKS2 \\
\hline Grup 1 & $7,6 \pm 1,27^{*}$ & $8,7 \pm 1,38^{*}$ \\
Grup 2 & $10,7 \pm 3,34$ & $10,8 \pm 3,25$ \\
Grup 3 & $11,7 \pm 3,30$ & $12,5 \pm 2,87$ \\
\hline
\end{tabular}

GKS1: YB'a ilk yatıştaki Glasgow koma skoru

GKS2: YB'dan taburcu olurken Glasgow koma skoru

${ }^{*}: p<0,05$

\begin{tabular}{|c|c|c|}
\hline \multirow[t]{4}{*}{ Hava yolu sorunları } & Trakeal aspirasyonun yapılamaması & $\% 16$ \\
\hline & Aşırı sekresyonlar ve tıkaç oluşumu & $\% 16$ \\
\hline & Trakeostomi kanül dislokasyonu & $\% 10$ \\
\hline & Mide içeriği aspirasyonu & - \\
\hline \multirow[t]{4}{*}{ MV sorunları } & Sık alarm vermesi & $\% 13$ \\
\hline & Ventilatörün basmaması & $\% 6$ \\
\hline & Hava kaçağı olması & $\% 6$ \\
\hline & Hastanın solunum sıkıntısının artması & $\% 3$ \\
\hline Diğerleri & & $\% 9$ \\
\hline
\end{tabular}

mortalite oranları Grup 1, 2 ve 3'te sırasıyla \%92,8, \%66,6 ve $\% 57,1$ olarak hesaplanmıştır.

GKS değerleri açısından Grup 1'in GKS 1 ve GKS 2 değerleri diğer gruplara göre anlamlı derecede düşük bulundu $(p<0,05)$. Her 3 grupta da anlamlı olmamakla birlikte GKS 2 değeri GKS 1'e göre daha yüksekti (Tablo 2). GKS 2 ve hasta yaşı ile evde yaşam süresi arasında anlamlı korelasyon vardı $(p<0,05)$.

Hasta bakıcılar ilk 1 hafta içinde YB hekimini aramadılar. Daha sonraki aramalarda hava yolu ve MV ile ilgili sorunlar ön planda idi (Tablo 3). Evde ölüm nedenleri, hava yolu sorunları (\%43) MV ile ilgili sorunlar (\%21) ve diğerleriydi (\%34).

Çalışmadaki tüm hastalar, PEG yoluyla enteral beslenme ile taburcu edildi.

\section{Tartışma}

2004-2010 yılları arasında genel YB kliniğimizde trakeostomi açılan hastaların \%30,9'unu evde bakım için trakeotomili olarak taburcu ettik. Hastaların \%20'si taburcu edildikten sonra 1 hafta içinde öldüler. Erken ve geç dönemde mortalitenin en sık nedenleri havayolu ve MV ile ilgili sorunlardı.

Marchese ve ark.'nın (7) çalışmasında, trakeostomi açılan hastaların \%22,5'nde trakeostomi kapatıımış, \%67,5'i trakeotomili olarak taburcu edilmiş ve trakeotomili taburcu edilenlerin de \%60,5'i MV desteğiyle taburcu edilmiş. Trakeostomiyle taburculuk oranlarının bizim çalışmadaki oranlardan daha yüksek olmasının nedenini YB mortalite oranlarının (\%10) düşük olmasına bağladık. Araştırmacılar mortalite oranındaki düşüklüğü, perkütan trakeostomiye bağlı olarak hastaların YB'dan ara üniteye erken transferine bağlamışlardır. Ancak araştırmacılar hastaların YB süreleri ve YB'da gelişen ciddi sorunlardan bahsetmemişlerdir. Muhtemelen yatış sürelerinin kısa oluşu ve ciddi komplikasyon gelişmemiş olması mortalite oranını düşürmüş olabilir. Bunun yanında çalışmamızda hastaların trakeostomili olarak taburcu edilmesinde çoğu zaman hasta yakınlarıyla ilgili engeller de vardı. YB ünitemizde, hasta klinik olarak taburculuğa hazır olmasına rağmen ailenin hasta bakımı için psikolojik, sosyal ya da ekonomik olarak hazır olmamalarından dolayı taburculuğu çoğu zaman geciktirmiştir ya da olmamıştır.

Çalışmamızda evde yüksek mortalite hızı tespit edilmiştir. Evde ölüm nedenlerinin en başında \%43 ile hava yolu sorunları, \%21 ile MV sorunları gelmiştir. Grup 1, 2 ve 3'te trakeostomi sonrası yaşam süreleri yaklaşık sırasıyla 11 ay, 18 ay ve 15 ay bulunmuştur. Çalışmamızda evde ölen hasta sayısı açısından gruplar arasında fark yoktu. Marchese (8) ve arkadaşlarının yaptığı benzer çalışmada KOAH'lı hastalarda ortalama yaşam süresi 26 ay iken, nöromusküler hastalıklarda 49 ay bulmuşlardır. Genel olarak evde ölüm nedenini altta yatan hastalığa bağlamışlardır. KOAH'lı hastalarda yaşam süreleri çalışmamızdaki ile benzer bulunmuştur. Nöromusküler hastalık grubu çalışmamızda 1 hastada görüldüğü için tartışılmadı. Marchese ve ark.'nın (8) çalışmasında ise SVH grubu belirtilmemiş ya da yoktu. Oysa ki çalışmamızda istatistiksel olarak anlamlı olmasa da evde mortalitenin en yüksek olduğu grup SVH grubu idi. YB ünitemizde hasta profilinin çoğu SVH hastalarıdır. Çalışmaya aldığımız hastaların \%46,6'sı SVH'lı hastalardı ve YB'a alındığında GKS ortalamaları 7,64 idi.

Çalışmalarda trakeotomi ile evde bakım gören hastaların konforunun iyi olduğu ve daha sonra benzer bir durumda aynı yöntemi tercih etikleri bildirilmiştir $(9,10)$. Bizim çalışmamızda hastaların GKS'u düşük olduğundan ve iletişim kurulamadığı için memnuniyet anketi yapılamamıştır. 
Evdeki hasta bakıcılarının karşılaşı̆̆ı sorunlar, memnuniyeti ve moral seviyesi de bakım etkinliğini belirleyen önemli faktörlerdendir. Bizim çalışmamızda hastaların çoğu MV desteği aldığı için hasta bakıcıların en çok şikayet ettiği sorun hava yolu (sekresyonları aspirasyonu) ve MV (sık alarm vermesi) ile ilgiliydi. Marchese ve ark.'nın (8) çalışmasında, hasta yakınlarının en büyük şikayetleri, hastanın anksiyetesi, kronik uyku sorunları ve hastayla ilgili ani ölüm korkuları olarak bildirilmiştir.

Evdeki sorunlardan bir diğeri, beslenme ile ilgilidir. PEG hastanın beslenmesinde konforu artırmasına ve bazı komplikasyonları azaltmasına rağmen, Golestanian ve ark. (11) akut SVH'da MV desteği ile birlikte PEG açımasını da kötü prognoz belirleyicisi olarak değerlendirilmişlerdir. Çalışmamızda, SVH'ı hastalarımızın hepsine PEG açımıştı. Bu gruptaki hastaların mortalitesinin yüksek olduğu düşünülürse, bizim çalışmamızda da PEG kötü prognoza işaret etmektedir.

Björling ve ark. (12) çalışmalarında, trakeostomi sonrası uzun dönem hastanede takip edilen hastalarda tahmini yaşam süresinin kısalmadığını ve hastane bakım intiyaçlarının artmadığını göstermişlerdir. Çalışmamızda bir maliyet araşıııması yapılmamasına karşın, hastane enfeksiyonları başta olmak üzere YB komplikasyonları, MV bağımlı YB hastalarının hastane maliyetini belirgin derecede artırmaktadır. Cox ve ark. (13) 2000'li yıllara kadar trakeostomi açılan hastaların çok küçük bir kısmını evde bakım için taburcu edebilmişlerdir. Böylece hastanede kalış süreleri ve hastane masrafları artmıştır. Bu çalışmada taburcu edilen hastaların sadece \%7'si MV desteği ile gönderilmiştir. Ancak bizim çalışmamızda eve gönderdiğimiz hastaların \%80'i MV destekli olduğu için evde de bakım maliyetinin de düşük olmayacağını söyleyebiliriz.

Evde bakım için gönderilen hastalar, Grup 1 hastalar daha fazla olmak üzere GKS 1 ve 2'si düşük, mobilize olmayan ve çoğu oral beslenemeyen hastalardı. Bu faktörler, evde mortalite oranlarının yüksek olmasıyla ilişkili olabilir. Zaten GKS 2'si düşük hastalarda evde yaşam süresi de düşük bulunmuştur. Çalışmamızda evde ilk 1 hafta mortalite oranı \%20 iken, bu 6 hastanın 4'ünde ölüm nedeni hava yoluna bağlı sorunlardan kaynaklanmıştır. Ikinci olarak MV'den kaynaklanan teknik sorunlar vardı. Hasta yakınlarına verilen eğitimin yeterli olduğunu düşünmekle beraber, özellikle ilk 1 hafta ev ortamına adaptasyon için önemli bir dönem olduğunu düşünüyoruz. Hasta bakıcıların ilk 1 hafta içinde YB hekimiyle iletişime geçmemesi de mortaliteyi artırmış olabilir. Belki de evdeki ilk birkaç haftalık dönemde YB hekimi tarafından yapılacak günlük ev ziyaretleri bu sıkıntıları azaltabilir.

Sonuç olarak, evde bakım için trakeostomiyle taburcu edilen hastaların mortalite oranları yüksek bulunmuştur. Bu hastaların çoğu MV destekli ve GKS'u düşüktü. Evde mortalitenin en önemli belirleyicileri olarak hava yolu ve MV sorunları gözlemlenmiştir. Bu sorunları azaltmak için daha sık hekim ziyareti gerektiği düşünülmektedir. GKS'u düşük trakeostomili hastaların evde bakım için taburcu edilmesi konusunda klinisyenlerin fayda zarar hesabını bir kez daha yapmaları gerektiğine inanıyoruz.

\section{Kaynaklar}

1. Sağıroğlu $A E$, Ağkoç $E$, Doğan $Y$. Yoğun bakım ünitesinde perkütan ve cerrahi trakeostominin karşılaştırılması. Göztepe Tıp Dergisi 2010;25:67-70.

2. Demirel I. Griggs Yöntemi lle Açılan 52 Olguda Perkütan Trakeostomi Sonuçlarımız. Fırat Tıp Dergisi 2010;15:140-2.

3. Cobb S. Presidential Address-1976. Social support as a moderator of life stress. Psychosom Med 1976;38:300-14.

4. Diard C, Ravaud JF, Held JP. French survey of postpolio sequelae. Risk factors study and medical social outcome. Am J Phys Med Rehabil 1994;73:264-7.

5. Make BJ, Hill NS, Goldberg Al, et al. Mechanical ventilation beyond the intensive care unit. Report of consensus conference of the American College of Chest Physicians. Chest 1998;113(Suppl. 5):289-344.

6. Kaplan A, Yaşar MA, Özer AB. Griggs, PerkuTwist ve Ciaglia Perkütan Trakeotomi Yöntemlerinin Karşılaştırılması. Fırat Tıp Dergisi 2010;15:173-7.

7. Marchese S, Corrado A, Scala R, Corrao S, Ambrosino N. Tracheostomy in patients with long-term mechanical ventilation: a survey. Respir Med. 2010;104:749-53.

8. Marchese S, Lo Coco D, Lo Coco A. Outcome and attitudes toward home tracheostomy ventilation of consecutive patients: a 10-year experience. Respir Med. 2008;102:430-6.

9. Moss $A H$, Oppenheimer EA, Casey $P$, et al. Patients with amyotrophic lateral sclerosis receiving long-term mechanical ventilation Advance care planning and outcomes. Chest 1996;110:249-55.

10. Moss $A H$, Casey $P$, Stocking $C B$, et al. Home ventilation for amyotrophic lateral sclerosis patients: outcomes, costs, and patient, family and physician attitudes. Neurology 1993;43:438-43.

11. Golestanian E, Liou JI, Smith MA. Long-term survival in older critically ill patients with acute ischemic stroke. Crit Care Med. 2009;37:3107-13.

12. Björling G, Johansson UB, Andersson G, Schedin U, Markström A, Frostell C. A retrospective survey of outpatients with longterm tracheostomy. Acta Anaesthesiol Scand. 2006;50:399-406.

13. Cox CE, Carson SS, Holmes GM, Howard A, Carey TS. Increase in tracheostomy for prolonged mechanical ventilation in North Carolina, 1993-2002. Crit Care Med. 2004;32:2219-26. 